\title{
The Design and Research of New Energy Vehicle Computer Circuit
}

\author{
Chen Hejuan \\ Wuxi Vocational Institute of Commerce, Wuxi, Jiangsu, 214153, China \\ email: chenhejuan@wxic.edu.cn
}

Keywords: New Energy Vehicle, Vehicle, Computer Circuit, Design Research

\begin{abstract}
Electric vehicle is a vehicle which uses all or part of electric power as power source. They don't have the fuel and exhaust emission problems of traditional cars. They have obvious advantages in cleaning, environmental protection and energy saving.
\end{abstract}

\section{Introduction}

At present, the energy and environmental problems of various countries are increasingly serious. As an indispensable means of transportation in human life. Shared bicycles play an important role in energy consumption and emissions. According to the data released by the government, at the end of 2012, the number of civil vehicles in China reached 1.2089 million, which will continue in the next few years, the National Bureau of Statistics said. The volume will continue to increase. And that makes China's energy shortage more and more serious. Cars bring people. At the same time, the pollution of the environment, automobile exhaust emissions cause greenhouse effect and ozone layer damage. Many environmental problems, such as acid rain, have brought great damage to human life. Electric cars are different from gasoline cars. Especially for pure electric vehicles, there is no fuel problem or vehicle exhaust problem, and Research on electric vehicles is under way. $\mathrm{R}$ \&amp; D is a hot topic in the world. At present, with the promotion of governments around the world, the major automobile enterprises in the world are actively providing new energy. The automobile can prepare for the rapid development in the international market. China's core technology in the traditional fuel automobile industry is far behind Europe, the United States and other industrial countries, but the gap between new energy vehicles, especially electric vehicles. It's not very big. It's also leading in some technologies.

\section{Prospect of New Energy Vehicles}

In January 1886, German engineer Carl Benz developed the world's first car. In the next few decades, automobile has played an important role in all aspects of human beings [1]. Automobile has greatly promoted people's life and brought unprecedented chaos to human beings. Nowadays, most cars use renewable resources as power. However, unburned fuel will release a lot of carbon dioxide and sulfur dioxide into the air. China has brought energy crisis, greenhouse effect and environmental pollution to the earth. Air pollution and noise pollution are the main problems caused by the development of automobile to the environment. With the increase of automobiles, air pollution in China has changed from industrial waste, coal smoke to photochemical smoke. In the big cities, the emission of CO is $60 \%$, the emission of NOX is $22 \%$, the emission of hydrocarbons is $73 \%$, and $66 \%$ of the air pollutants in the United States contain Co, $43 \%$ NOX and HC. 31\% and $33 \%$ of CO $\%$ and $20 \%$ of CO are from automobile emissions. Since the 1970 s, the country has invested a lot of human and material resources for treatment, but there are still a lot of waste discharged into the atmosphere through cars every year. It is clear that the annual emissions of the world's automobiles were 4.4 billion tons in 1990 and 49 billion tons in 2000. As a result, air pollution from automobile emissions has become the main cause of the world's air pollution sources [2]. According to the data released by the China Environment Program in 2000, 63.5 of the 388 cities exceeded the state's secondary air standard, 112 of which exceeded the tertiary air standard. According to the 2010 domestic and foreign oil and natural gas industry development report 
released by PetroChina, before 2011, China's oil consumption will be more than 483 tons, the consumption of refined oil products will reach 257 tons, and the consumption of automobile gasoline will be 7460. 10000 tons, diesel consumption 150 million tons. In addition, according to the analysis, the national oil demand will reach 540 million tons in 2015, and its external dependence will rise to more than 60\%. According to the International Environmental Research Institute, there are now seven of the top 10 most polluted cities in China. China's national environmental protection center predicts that automobile exhaust emissions account for about $70 \%$ of air pollution sources [2]. In order to protect the natural environment, many countries begin to pay attention to environmental protection. Many countries, especially developed countries in the west, have formulated and implemented stricter automobile emission standards. New energy vehicles have less pollution and few emissions, which can greatly reduce urban air pollution and greenhouse effect. Since the world's third oil crisis in the 1980s, the earth's resource shortage has become more and more serious. Because of the shortage of resources caused by air pollution, governments all over the world have realized the importance of energy conservation and emission reduction [3]. Having sex? With the closure of the global climate conference in Copenhagen, the Chinese government will intervene more in the world. By 2025, as shown by the central economic and industrial conference, it will cut by $45 \%$ from 2000 . In addition, seven main fields, such as new energy, electric vehicle, energy conservation, environmental protection, information and communication, biology, medicine, new materials, and biological breeding, are discussed. Active research on electric vehicles is the best way to save energy and reduce emissions, and it is also an important direction of future automotive technology progress. With the rapid development of China's economy, China's automobile ownership exceeds the world's average ownership. With the rapid increase of automobile ownership, the air pollution and greenhouse effect caused by the emission of traditional gasoline vehicles become more and more serious. According to the electric energy needed by pure electric vehicles, it can be obtained from possible energy at one time through various conversion technologies, water power, wind power, water power, energy and atomic energy. Moreover, it can fully use low power consumption at night to charge the battery. Therefore, reducing carbon dioxide emissions and energy conservation of electric vehicles has become an important long-term strategy for their research and development.

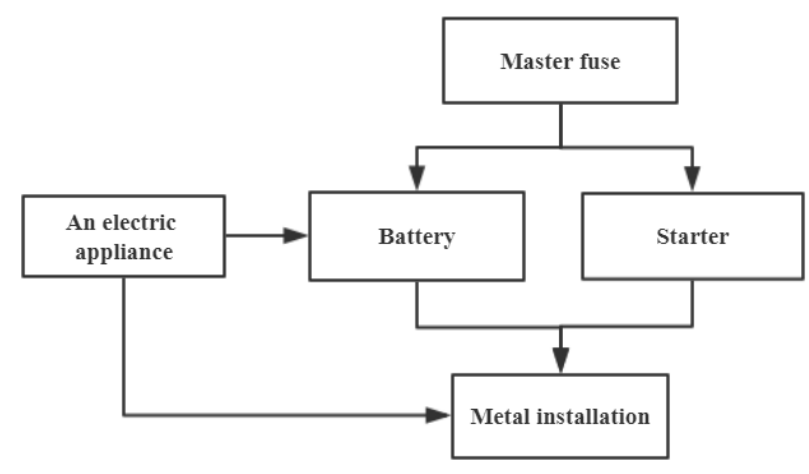

Figure 1 Schematic diagram of main fuse

\section{The Application of Car Computer}

With more and more functions of new energy vehicle electronic equipment, consumers have higher and higher requirements for it, including on-board computer system [4]. The development of the system is very rapid, GPS vehicle navigation market has entered a high-speed development stage, and has been applied in many vehicles. When the car is put into use, with the gradual improvement of the function and performance of electronic components, how to multimedia the home. Move the entity entertainment system to the new energy vehicle and enjoy the convenience of the vehicle as a means of transportation. With comfortable driving and driving environment, it 
has become a new application of integration of new energy vehicle industry and electronic industry. For new energy vehicle products, the domestic entertainment system is mainly vehicle video entertainment system, including vehicle. Audio, car TV, car DVD and so on, then how to combine all these functions. It is a very promising development direction.

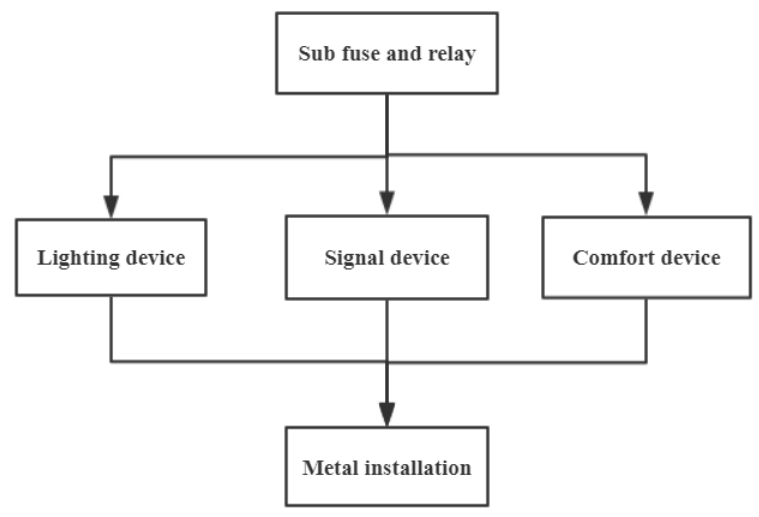

Figure 2 Schematic diagram of sectionalizer and relay

\section{On Board Computer}

The traditional host is an embedded system. IEEE according to the definition of embedded system. Operation monitor or auxiliary of machinery device [5]. This is mainly from the application application. By definition, you can see that an embedded system is a combination of software and hardware. However, the above definition cannot be made. It reflects the nature of a fully embedded system. Now in China, the commonly accepted definition is: as the center. Based on computer technology, software and hardware can coordinate the function, reliability and success of the application system. "A special computer system with strict requirements for size, volume and power consumption is simply a placement and embedding system." Application software and hardware, as BIOS works on a personal computer, are integrated with software code. Small, high-speed features such as automation and high-speed response are especially suitable for systems requiring real-time and multitasking. Embedded system is mainly composed of embedded processor, related hardware, embedded operating system and application software system. From the perspective of basic application, embedded system, general computer and other applications [6]. Compared with the system, it has the following characteristics.

\subsection{Strong Specificity}

Because embedded systems are usually oriented to specific applications, they are embedded systems. Hardware and software, especially software, are designed for specific user groups.

\subsection{Good Real-Time Performance}

At present, embedded system is widely used in production engineering control. Data collection, transmission, communication and other opportunities are mainly used to control host objects, all of which are more or less available in embedded systems, such as real-time embedded systems for embedded weapon devices. The embedded system of rocket 1. In some industrial controller applications, such as control system, the real-time requirements are very high. Because that's right, so that's necessary. Embedded system does not use low speed access disk and other memory especially in hardware. By careful design, the embedded system can quickly respond to external events. Embedded system. General requirements are important indicators to focus on designers and users.

\subsection{Good Tailorability}

From the perspective of the specificity of embedded system, as the supplier of embedded system. 
We need to provide all kinds of hardware and software. However, this will inevitably increase the cost of the product. In order to improve the cost and meet the specific needs, the embedded system supplier must take corresponding measures [7]. Keep the balance between general products and special products. " The current method is to design and assemble the system hardware and operating system, so that the developers of embedded system can measure the volume according to the actual application requirements. By adjusting and removing redundancy, the system can achieve the most reasonable configuration under the premise of the required application requirements.

\subsection{High Reliability}

Because some embedded systems perform computing tasks that include product quality. In addition to other main problems, some embedded system host objects operate in the case of nobody. Dangerous industrial environment [8]. Compared with the common system, the small intelligent equipment has very high requirements for the embedded system, which is used to detect the detection system operated by the enemy in the place where it is difficult to embed into the instrument.

\subsection{Low Power Consumption}

There are many embedded systems, in which the host object is a small application system, such as mobile. Telephone. Aircraft. Ships. It is difficult to use the digital camera for large capacity. Power, therefore, low power consumption is always required after the target of embedded system [9]. Of course, it reduces the power consumption of the system. The software embedded in the system is usually not stored on the disk or other carriers, but solidified by memory chip or single chip. System memory.

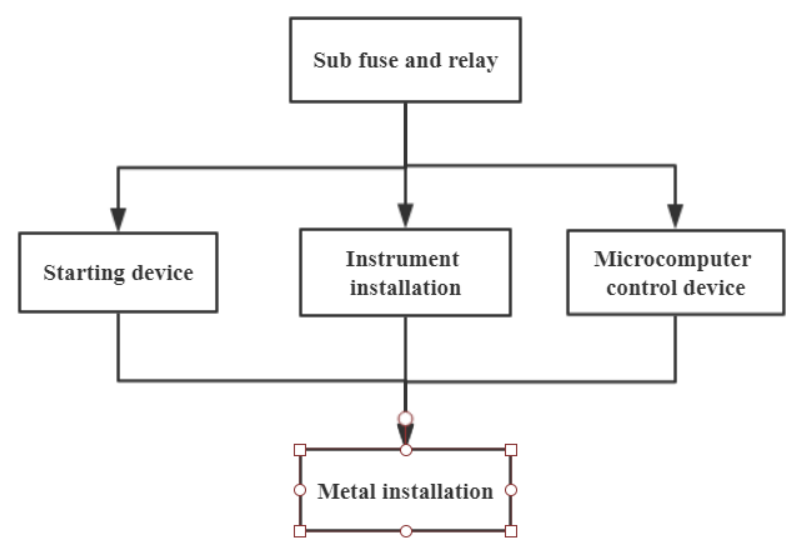

Figure 3 Schematic diagram of the last part of the whole vehicle electrical system

\section{Circuit Principle of New Energy Vehicle}

The automobile circuit is usually very complex. The automobile circuit block diagram is usually used to represent the automobile circuit system. The basic structure, features, and circuit diagrams of interconnected vehicles are marked or annotated. The box is a simple diagram showing the basic structure, characteristics and interrelationship of automobile electrical system [10]. Automobile circuit. The block diagram generally does not describe the circuit content, but mainly uses graphic symbols and annotation boxes to describe the main functions of the system. Automobile functional block diagram is the initial product of automobile electrical system design. According to the classification structure of the electrolysis system, the gas system is derived in the order of function decomposition.

\section{Conclusion}

According to the functional requirements of vehicle circuit system design, the safety, reliability 
and economy of the system are fully considered. Under natural conditions, the overall design of the circuit system and the optimal design and configuration of each component are completed.

\section{Acknowledgements}

General Project of Jiangsu Natural Science Foundation: Research on Energy Storage of Supercapacitors with 3D Ordered Macroporous Composite Electrode Materials (19KJB480011).

\section{References}

[1] HUA YUEMING, CHU LEIFANG. INTERIOR SPACE DESIGN OF NEW ENERGY VEHICLE. Design, 2018.

[2] Zhuhaitao, Zhangxianglei, Yangjialin,. Characteristics Numerical Research on Power Battery Impact Strength of New Energy Vehicle. International Journal of Computational Methods, no. 17, 2019.

[3] Yuanli L I. TALKING ABOUT THE DESIGN OF NEW ENERGY VEHICLE FROM "THE UNDERSTANDING OF PEOPLE". 2018.

[4] Akhil Garg, V. Vijayaraghavan, Jian Zhang,. Design of robust battery capacity model for electric vehicle by incorporation of uncertainties: Design of a robust battery capacity model. International Journal of Energy Research, vol. 41, no. 10, 2017.

[5] Meng D, Yu Z, Zhou M, et al. Intelligent fuzzy energy management research for a uniaxial parallel hybrid electric vehicle, vol. 58, no. C, pp. 447-464, 2017.

[6] Xie L, Li J, Li X, et al. Damping-tunable energy-harvesting vehicle damper with multiple controlled generators: Design, modeling and experiments, vol. 99, pp. 859-872, 2018.

[7] Menell, Peter S, Nimmer, David, Green, Kevin. Why the Ninth Circuit's Antonick v. Electronic Arts Case Is an Ideal Vehicle for Addressing the Circuit Split Over Admissibility of Expert Testimony in Software Copyright Cases. Social Science Electronic Publishing, 2017.

[8] G. Gao, P. Chen. Research on Vehicle-mounted Vacuum Circuit Breaker Interrupting Overvoltage. Journal of the China Railway Society, vol. 39, no. 10, pp. 62-67, 2017.

[9] Ali Saadon Al-Ogaili, Ishak Bin Aris, A. H. Sabry,. Design and development of three levels universal electric vehicle charger based on integration of VOC and SPWM techniques. Journal of Computational and Theoretical Nanoscience, vol. 14, no. 10, pp. 4674-4685, 2017.

[10] Fei Lu, Hua Zhang, Chris Mi. A Two-Plate Capacitive Wireless Power Transfer System for Electric Vehicle Charging Applications. IEEE Transactions on Power Electronics, no. 99, pp. 1-1, 2017. 